\title{
Structural and electronic properties of the spinel $\mathrm{Li}_{4} \mathrm{Ti}_{5} \mathrm{O}_{12}$
}

\author{
Sarantuya Lkhagvajav ${ }^{1^{*}}$, Namsrai Tsogbadrakh², Enkhjargal Enkhbayar ${ }^{1}$, \\ Sevjidsuren Galsan ${ }^{1}$, Pagvajav Altantsog ${ }^{1}$ \\ ${ }^{1}$ Institute of Physics and Technology, Mongolian Academy of Sciences, Ulaanbaatar 13330, Mongolia \\ ${ }^{2}$ Department of Physics, National University of Mongolia, Ulaanbaatar 14201, Mongolia \\ *Corresponding author: saraa.ipt@gmail.com; ORCID ID:0000-0001-7508-5326
}

Received: 25 June 2019; revised: 5 September; accepted: 11 September 2019

\begin{abstract}
In this study, the structure and electronic properties of the spinel compound $\mathrm{Li}_{4} \mathrm{Ti}_{5} \mathrm{O}_{12}(\mathrm{LTO})$ are investigated both theoretical and experimental methods. The experimental studies of structural and electronic properties were performed by $\mathrm{X}$-ray diffraction and UV-visible spectroscopy. The first principles calculations allowed to establish the relationship between the structure and electronic properties. The spinel type structure of LTO is refined by the Rietveld analysis using the X-ray diffraction (XRD). The band gap of LTO was determined to be $3.55 \mathrm{eV}$ using the UV-visible absorption spectra. The Density functional theory (DFT) augmented without and with the Hubbard $U$ correction $\left(G G A\right.$ and $\left.G G A+U+J_{0}\right)$ is used to elucidate the electronic structure of LTO. We have performed systematic studies of the first principles calculations based on the GGA and GGA+U for the crystal structure and electronic properties of spinel LTO. We propose that a Hubbard $U$ correction improves the DFT results.
\end{abstract}

Keywords: Spinel, $\mathrm{Li}_{4} \mathrm{Ti}_{5} \mathrm{O}_{12}$, DFT, GGA + U, X-ray diffraction, UV-visible

\section{INTRODUCTION}

The spinel type $\mathrm{Li}_{4} \mathrm{Ti}_{5} \mathrm{O}_{12}$ (LTO) is one of the most promising anode materials for the lithium ion batteries due to features of excellent structural stability, high power density, long cycle life and environmental tolerance [1-4]. Deschanvres et al. reported on a spinel phase of lithium titanium oxides described as $\mathrm{Li}_{1+x} \mathrm{Ti}_{2-\mathrm{x}} \mathrm{O}_{4}(0<\mathrm{x}<1 / 3)$ in the Li-Ti-O system [5]. Numerous studies were carried out since spinel LTO was first introduced as an anode material for lithium ion batteries [6]. The slight volume change in the charge/discharge process is among the most important characteristics of this material [7]. Since spinel LTO is a zero - strain insertion material, this property governs the extraordinary cycling stability of LTO. Therefore, the insertion and extraction of lithium are reversible [8]. It was clearly shown in several investigations that volume change of the LTO crystal during the charge/discharge cycling is less than $0.2 \%$ [9]. These advantages make LTO become the most promising anode materials for the lithium ion batteries applied in large scale energy storage and electronic devices [10, 11]. The spinel LTO compound has a cubic structure with a space group symmetry $\mathrm{Fd} 3^{-} m$ (No - 227) [12]. In the spinel structure, lithium atoms occupy all the tetrahedral 8 a sites. The octahedral $16 \mathrm{~d}$ sites are occupied randomly by lithium atoms $1 / 6$ and titanium atoms $5 / 6$ and all the 32 e sites are fully occupied with $O$ atoms [13-16]. Therefore, its empirical formula is written as $[\mathrm{Li}]^{8 \mathrm{a}}\left[\mathrm{Li}_{1 / 3} \mathrm{Ti}_{5 / 3}\right]^{16 \mathrm{~d}} \mathrm{O}_{4}{ }^{32 \mathrm{e}}$ [17]. The theoretical capacity of spinel lithium titanate is $175 \mathrm{mAh} / \mathrm{g}$ [18]. This material works between the delithiated state spinel $\mathrm{Li}_{4} \mathrm{Ti}_{5} \mathrm{O}_{12}$ and lithiated state rock salt $\mathrm{Li}_{7} \mathrm{Ti}_{5} \mathrm{O}_{12}$ [19], where three $\mathrm{Li}^{+}$ions can be intercalated electrochemically in spinel LTO at flat potential of $1.55 \mathrm{~V}$ vs $\mathrm{Li}^{2} \mathrm{Li}^{+}$[20]. During intercalation process, lithium moves from tetrahedral 8 a sites toward the octahedral $16 \mathrm{c}$ sites $[21,22]$. The reaction equation of such system is written as:

$$
\mathrm{Li}_{4} \mathrm{Ti}_{5} \mathrm{O}_{12}+3 \mathrm{Li}^{+}+3 \mathrm{e}^{-}=\mathrm{Li}_{7} \mathrm{Ti}_{5} \mathrm{O}_{12}
$$

To enhance the electrical performance of LTO many techniques are being used, such as doping aliovalent atoms $\left(\mathrm{Sc}^{3+}, \mathrm{Ta}^{5+}, \mathrm{V}^{5+}, \mathrm{Nb}^{5+}, \mathrm{Al}^{3+}, \mathrm{Mg}^{2+}\right)$, size reduction, surface coating or hybridizing with conductive materials (Ag, Cu, C and graphene) [23, 24].

In this paper, we report the the structural and electronic properties of the spinel LTO evaluated by X-ray diffraction analysis, UV-visible spectrometry and the first principles calculations. Here, the simulation results are compared with the experimental data. 


\section{EXPERIMENTAL}

The LTO was prepared by solid state reaction method. The raw materials $\mathrm{TiO}_{2}$ (99.9\%, Sigma Aldrich) and $\mathrm{Li}_{2} \mathrm{CO}_{3}$ (99.9\%, Sigma Aldrich) were mixed by ball milling for $24 \mathrm{~h}$ and then calcined at $800^{\circ} \mathrm{C}$ for $2 \mathrm{~h}$ in the air in the same technique as described in our previous investigation [25]. The powder X-ray diffraction (XRD) data of the sample was collected on a Maxima-X7000 diffractometer for the diffraction angles between 100 and 900 with the increment of 0.020 . The lattice parameter is obtained from the Rietveld refinement. To this end, the Rietveld refinement was performed with Fullprof software using Pseudo-Voigt peak function [26-29]. Further, the crystallite size in the sample was estimated by the Scherrer equation from XRD pattern. The UV-visible absorption spectra measurements were carried out on a Shimadzu UV-2550 UV-visible spectrometer over the spectral range from 200 to 800 $\mathrm{nm}$ with $\mathrm{BaSO}_{4}$ as the background. The data processing was performed with the UV Probe software.

Computational details: The calculations are based on the projector augmented wave (PAW) selfconsistent field method using the generalized gradient approximation (GGA) proposed by Perdew, Burke and Enzerhof (PBE) [30] within the framework of density functional theory (DFT) [31, 32], as implemented in the QUANTUM ESPRESSO package [33]. The interaction between the ions and valence electrons is expressed as the ultrasoft pseudopotential [34]. The following electronic states are treated as valence states: $\mathrm{Li}\left(1 \mathrm{~s}^{2} 2 \mathrm{~s}^{1}\right)$, Ti $\left(3 s^{2} 3 p^{6} 3 d^{2} 4 s^{2}\right)$ and $O\left(2 s^{2} 2 p^{4}\right)$. The wave functions are expressed as plane waves up to a kinetic energy cutoff of 40 Ry and the kinetic energy cutoff for charge density and potential is chosen as 320 Ry. The threedimensional Fast Fourier Transform (FFT) meshes for charge density, SCF potential and wave function FFT and smooth part of charge density are chosen to be $(60$ $x 60 \times 60$ ) grids. There might be need to use finer k-points meshes for a better evaluation of on - site occupations in the strong correlated system. The summation of charge densities is carried out using the special k-points restricted by the $(5 \times 5 \times 5)$ grids of Monkhorst - Pack scheme due to the computer power ability [35]. The tetrahedral method is used when the electronic densities of state (DOS) are evaluated [36]. To obtain the optimized atomic structures, ionic positions and lattice parameters are fully relaxed until the residual forces are less than $0.05 \mathrm{eV} / \AA$ for each atom. The occupation numbers of electrons are expressed by Gaussian distribution function with an electronic temperature of $\mathrm{k}_{\mathrm{B}} \mathrm{T}=0.02$ Ry. The mixing mode of charge density is chosen to be local density dependent Tomas - Fermi (TF) screening for highly inhomogeneous systems. Its mixing factor for self- consistency is to be 0.2 and the number of iterations used in mixing scheme is 5 . The generalized eigenvalue problem is solved by the iterative diagonalization using the conjugate gradient (CG) minimization technique, and the starting wave function is chosen from superposition of atomic orbitals plus a superimposed "randomization" of atomic orbitals in all our calculation [33, 37]. In order to express the strong correlated effect of electrons in the Ti-3d state, we used the extended Hubbard - based Hamiltonian including the effective magnetic exchange interaction parameter $J_{0}$ and the on - site Coulomb interaction is chosen to be $U=4-8 \mathrm{eV}$ using the simplified rotational - invariant formulation based on the linear response method [38]. The Hubbard parameter, which is used to the perturbation to compute $\mathrm{J}_{0}$ with the linear - response method, is chosen to be $1 \mathrm{eV}$ [39]. Atomic wave functions used for $\mathrm{GGA}+\mathrm{U}+\mathrm{J}_{0}$ projector were not orthogonalized.

\section{RESULTS AND DISCUSSION}

The X-ray diffraction patterns of synthesized LTO are shown in Figure 1. All the sharp diffraction peaks can be indexed on the basis of a cubic spinel structure, $\mathrm{Li}_{4} \mathrm{Ti}_{5} \mathrm{O}_{12}$ (JCPDS Card No.490207) and no impurity peaks can be found.

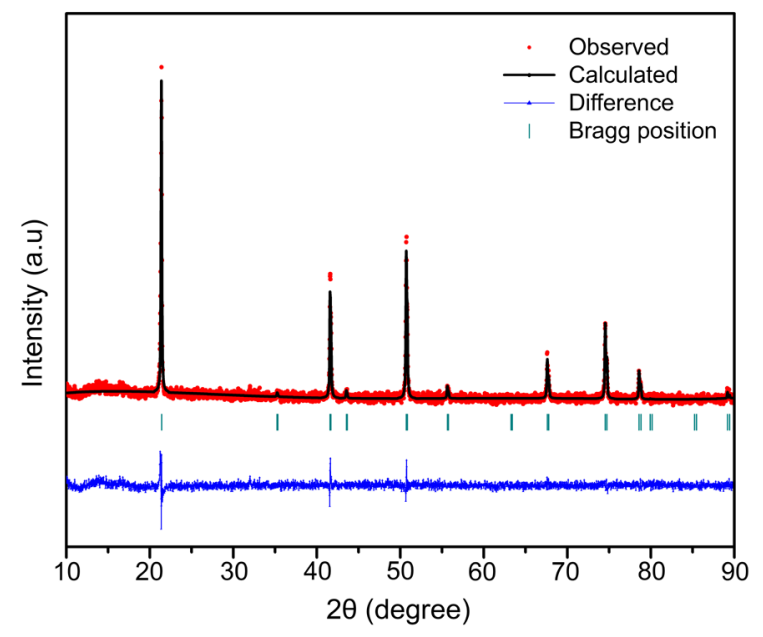

Fig. 1. X-ray diffraction patterns of $\mathrm{Li}_{4} \mathrm{Ti}_{5} \mathrm{O}_{12}$.

The peaks at $2 \theta=21.3,35.2^{\circ}, 41.5^{\circ}, 43.5^{\circ}, 50.7^{\circ}, 55.6^{\circ}$, $63.2^{\circ}, 67.6^{\circ}, 74.5^{\circ}, 78.6^{\circ}, 79.9^{\circ}, 85.2^{\circ}$ and $89.1^{\circ}$ are corresponded to (111), (220), (311), (222), (400), (331), (422), (511), (440), (531), (442) (620) and (533) planes of a face centered cubic spinel $\mathrm{Li}_{4} \mathrm{Ti}_{5} \mathrm{O}_{12}$ with a space group, respectively. The structural parameters of LTO obtained using Rietveld refinement are summarized in Table 1. The crystallite size of LTO calculated by Sherrer equation is about $80 \mathrm{~nm}$.

Table 1. The results of Rietveld Analysis of X-ray diffraction data for LTO.

\begin{tabular}{clcccc}
\hline Site & Atom & $\mathbf{X}$ & $\mathbf{Y}$ & $\mathbf{Z}$ & Occupancy \\
\hline 8a & $\mathrm{Li}(1)$ & 0.00000 & 0.00000 & 0.00000 & 1.000 \\
16d & $\mathrm{Li}(2)$ & 0.62500 & 0.62500 & 0.62500 & 0.503 \\
16d & $\mathrm{Ti}$ & 0.62500 & 0.62500 & 0.62500 & 0.497 \\
32e & $\mathrm{O}$ & 0.38945 & 0.38945 & 0.38945 & 1.000 \\
\hline
\end{tabular}


The lattice parameter from Rietveld refinement was obtained to be 8.3558 (3) $\AA$. The intensities well exhibit the space group of $[F(R) h v]^{1 / 2}$. This result indicated that the pure spinel LTO powder was successfully obtained.

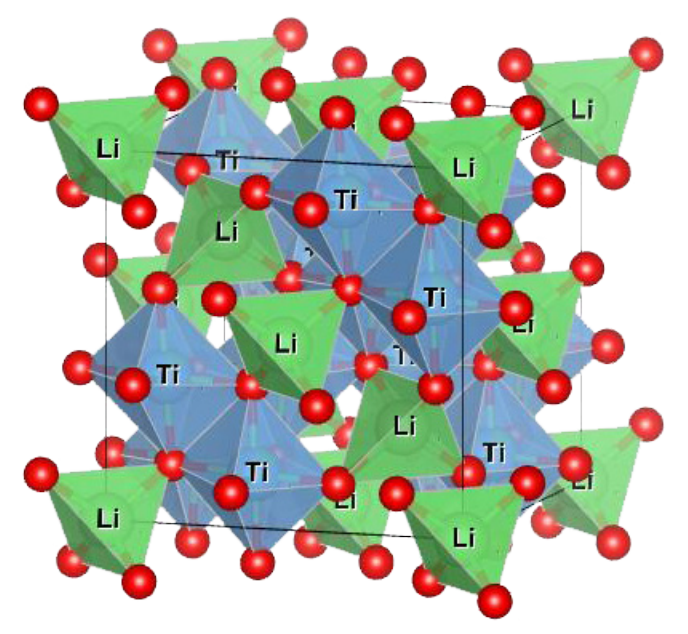

Fig. 2. The unit cells of the LTO, where the green tetrahedrons, blue octahedrons and red spheres represent $\mathrm{Li}$ ions at the $8 \mathrm{a}$ site, $\mathrm{Li}$ and $\mathrm{Ti}$ ions at the $16 \mathrm{~d}$ site, and $\mathrm{O}$ ions at the $32 \mathrm{e}$ site, respectively.

The crystal structure of LTO is shown in Figure 2. Here, lithium atoms are occupying all the tetrahedral $8 \mathrm{a}$ sites. Blue octahedral $16 \mathrm{~d}$ sites are occupied randomly by lithium atoms $1 / 6$ and titanium atoms $5 / 6$, and the $32 \mathrm{e}$ sites are fully occupied by $\mathrm{O}$ atoms. In order to further elucidate the structural and electronic properties of spinel LTO, the DFT analysis was used. The lattice parameter of the unit cell is optimized for different values of $U$ ranging from 4 to $8 \mathrm{eV}$. The calculated lattice parameters for selected $U$ values are presented in Table 2. The calculated lattice parameter increased up to $8.6948 \AA$ with increase of $U$ values. Our calculated values are estimated to be 2-3\% higher than experimentally defined value (8.3558 $\AA$ ).

Table 2. The optimized lattice parameters and the band gap $\left(\mathrm{E}_{\mathrm{g}}\right)$ of $\mathrm{Li}_{4} \mathrm{Ti}_{5} \mathrm{O}_{12}$ as a function of Hubbard parameter U by PAW - GGAand PAW - GGA $+U+J_{0}$

\begin{tabular}{lll}
\hline $\mathbf{U}(\mathrm{eV})$ & $\mathbf{a}=\mathbf{b}=\mathbf{c}(\AA)$ & $\mathrm{E}_{\mathrm{g}}(\mathrm{eV})$ \\
\hline 0 & 8.4124 & 3.16 \\
4 & 8.5735 & 3.24 \\
5 & 8.6005 & 3.34 \\
6 & 8.6280 & 3.44 \\
7 & 8.6570 & 3.58 \\
8 & 8.6948 & 3.54 \\
\hline
\end{tabular}

In Figure 3a, the UV-visible spectra of spinel LTO are shown. The cut off edge is observed at $282 \mathrm{~nm}$. The band gapof LTO can be evaluated from the UV-vis spectra by Tauc plot of versus (hv) and extrapolation of the linear portion of the curve to the energy axis according to [40]:

$$
E-E_{g}=\left\{\left(\frac{4 \pi k}{\lambda}\right) \frac{h v}{B}\right\}^{1 / 2}
$$
where, $\mathrm{E}$ is the photon energy, $\mathrm{B}$ is a constant, $\alpha=\frac{4 \pi k}{\lambda}$
and $\mathrm{k}$ are the absorption and extinction coefficients respectively. As shown in Figure $3 \mathrm{~b}$, the band gap energy of LTO estimated by extrapolating the linear part of $[F(R) h v]^{1 / 2}$ plot to the energy axis is 3.55 $\mathrm{eV}$. Hence, spinel LTO is an insulating material, which the bandgap is defined by the occupied $0-2 p$ valence states and empty Ti-3d conduction band [8].
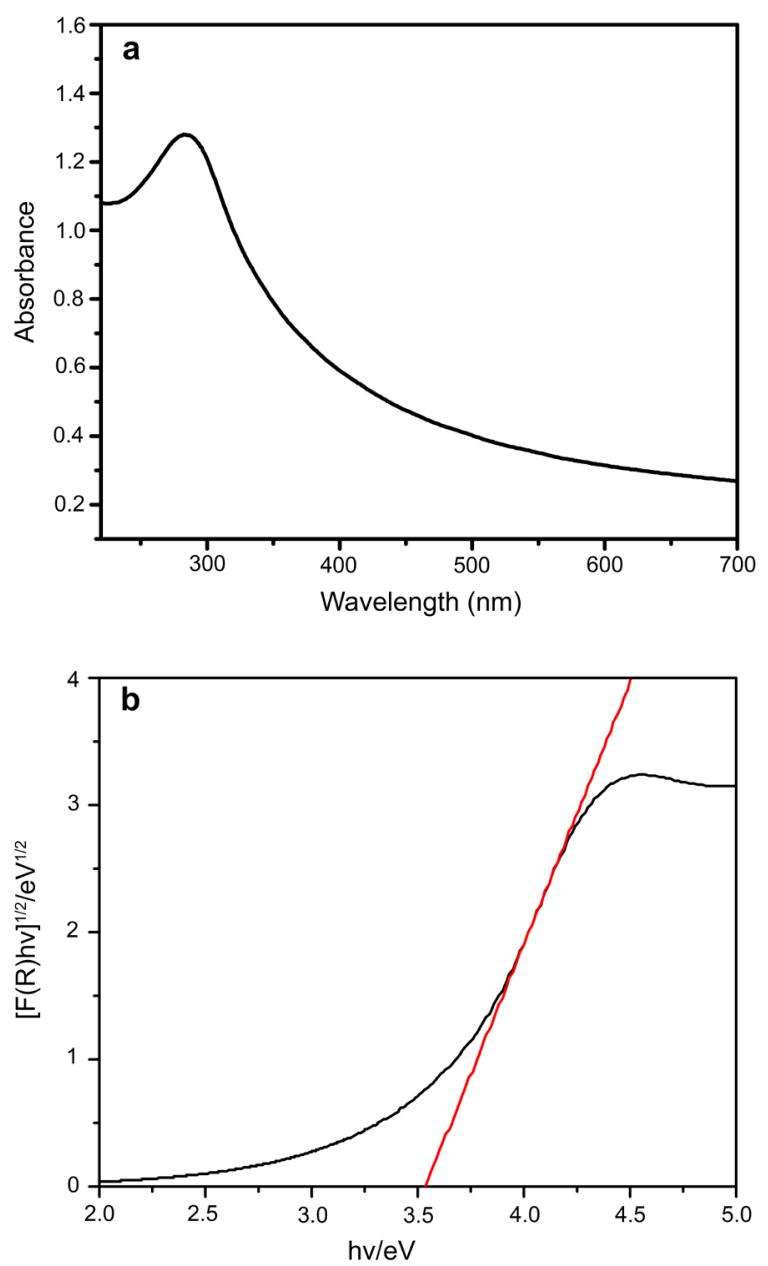

Fig. 3. a) The UV-vis absorption spectra of $\mathrm{Li}_{4} \mathrm{Ti}_{5} \mathrm{O}_{12}$, b) TheTauc plot for $\mathrm{L}_{\mathrm{i} 4} \mathrm{Ti}_{5} \mathrm{O}_{12}$.

In order to investigate the electronic properties of LTO, the band structure calculation is implemented. The total and orbital projected density of states (TDOS \& PDOS) of LTO for different $U$ values are presented in Figure 4. The band gap values of LTO are summarized in Table 2, and these values are calculated to be in the range of $3.24-3.58 \mathrm{eV}$. From these data, one can see that band gaps at $\mathrm{U}=7$ and $8 \mathrm{eV}$ are relatively close to the experimental result. For $U=7 \mathrm{eV}(\mathrm{U}=$ $8 \mathrm{eV})$, the occupied bands of $0-2 p$ state are sited at the energy range between the $-5.13 \mathrm{eV}$ and $-1.99 \mathrm{eV}$ 
( $-5.15 \mathrm{eV}$ and $-1.99 \mathrm{eV})$ below the Fermi level in the valence band. The unoccupied Ti-3d states are sited in the energy range between 2.01 and $2.59 \mathrm{eV}$ (1.93 and $2.73 \mathrm{eV}$ ) above the Fermi level in the conduction band.

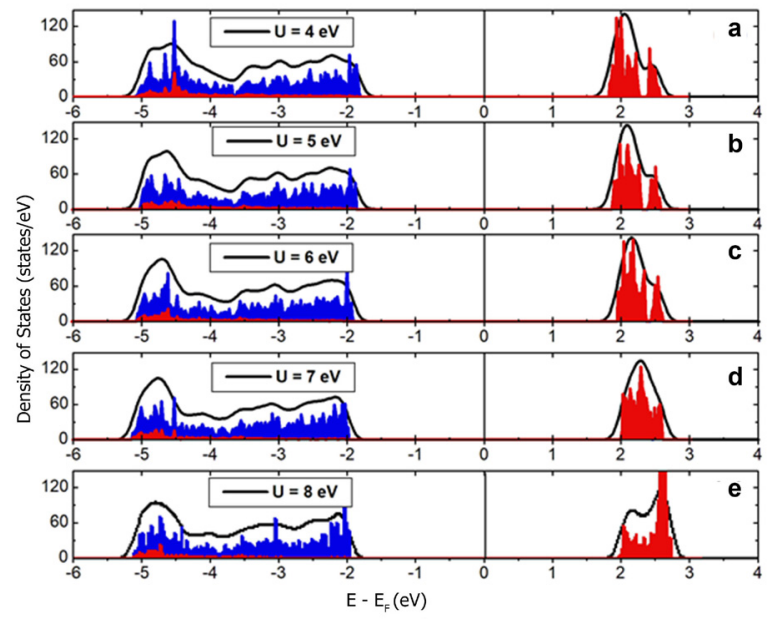

Fig. 4. The total and orbital projected densities of states (TDOS and PDOS) of LTO. The blueand red colors are the orbital projected density of states (PDOS) of O-2p and Ti-3d orbitals respectively. The vertical solid line corresponds to Fermi level.

It is shown that the unoccupied Ti-3d states are slightly broadening at $\mathrm{U}=8 \mathrm{eV}$ due to the Coulomb repulsion of the Ti-3d states. These values are in good agreement with theoretical and experimental values reported by Ouyang et al [8] and Kim et al [41] where band gap from 2 to $3.8 \mathrm{eV}$ belongs to insulator. The increase of $\mathrm{U}$ up to $7 \mathrm{eV}$ relates to the increase of the band gap of spinel LTO and band gap decrease was noticed at $\mathrm{U}=8 \mathrm{eV}$. When parameter $\mathrm{U}$ becomes 7 and $8 \mathrm{eV}$, the bandgap value of LTO stabilized at around $3.54-3.58$ $\mathrm{eV}$. Thus, the bandgap is predicted to be about $3.54 \mathrm{eV}$.

\section{CONCLUSIONS}

In this study, the crystal structure and electronic properties of spinel LTO have been determined with the experimental and theoretical methods. The cubic spinel structure ( $\mathrm{Fd} 3^{-} \mathrm{m}$ space group) with cell parameter $a=8.3558 \AA$ structure was identified by the $\mathrm{X}$-ray diffraction method. The analysis of the UV-visible spectra of LTO demonstrates a band gap of about 3.55 $\mathrm{eV}$. The GGA + U+ J approach was used in investigation of the structural and electronic properties of LTO. The predicted cell parameters values are estimated to be 2-3 \% higher than experimentally defined value.The calculated electronic structures shown that the spinel LTO is an insulator with band gap defined by the occupied $\mathrm{O}-2 \mathrm{p}$ states and empty Ti - 3d states. The calculated band gap value is found to be $3.54 \mathrm{eV}$, which is in good agreement with the experimental result.

\section{ACKNOWLEDGMENTS}

This work was partially supported by the Mongolian Foundation of Science and Technology (Project No 4381) and Internal Project No P2018-3612 of National University of Mongolia. We thanks for performing the calculations on the server computers at the School of Applied Science and Engineering in the National University of Mongolia.

\section{REFERENCES}

1. Ohzuku T., Ueda A., Yamamoto N. (1995) Zerostrain insertion material of $\mathrm{Li}\left[\mathrm{Li}_{1 / 3} \mathrm{Ti}_{5 / 3}\right] \mathrm{O}_{4}$ for rechargeable lithium sells. J. Electrochem. Soc., 142, 1431-1435. doi: 10.1149/1.2048592

2. FehrK T., Holzapfel M., Laumann A., Schmidbauer E. (2010) DC and AC conductivity of $\mathrm{Li}_{4 / 3} \mathrm{Ti}_{5 / 3} \mathrm{O}_{4}$ spinel. Solid State lonics, 181, 1111-1118. doi:10.1016/j.ssi.2010.05.026

3. Li J., Jin Y., Zhang X., Yang H. (2007) Microwave solid-state synthesis of spinel $\mathrm{Li}_{4} \mathrm{Ti}_{5} \mathrm{O}_{12}$ nanocrystallites as anode material for lithiumion batteries. Solid State lonics, 178, 1590-1594. doi:10.1016/j.ssi.2007.10.012

4. Shi Y., Wen L., Li F., Cheng H.M. (2011) Nanosized $\mathrm{Li}_{4} \mathrm{Ti}_{5} \mathrm{O}_{12}$ /graphene hybrid materials with low polarization for high rate lithium ion batteries. J. Power Sources, 196, 8610-8617. doi:10.1016/j. jpowsour.2011.06.002

5. Deschanvers A., Raveau B., Sekkal Z. (1971) Mise en evidence et etude cristallographique d'une nouvelle solution solide de type spinelle $\mathrm{Li}_{1+\mathrm{x}} \mathrm{Ti}_{2-\mathrm{x}} \mathrm{O}_{4}(0.33)$. Mater. Res. Bull., 6, 699-704. doi:10.1016/0025$\underline{\text { 5408(71)90103-6 }}$

6. Sun X., Radovanovic P.V., Cui B. (2015) Advances in spinel $\mathrm{Li}_{4} \mathrm{Ti}_{5} \mathrm{O}_{12}$ anode materials for lithium-ion batteries. New J. Chem., 39, 38-63. doi:10.1039/ C4NJ01390E

7. Scharner S., Weppner W., Schmid-Beurmann P. (1999) Evidence of two-phase formation upon lithium Insertion into the $\mathrm{Li}_{1.33} \mathrm{Ti}_{1.67} \mathrm{O}_{4}$ spinel. J. Electrochem. Soc., 146, 857-861. doi:10.1149/1.1391692

8. Ouyang C.Y., Zhong Z.Y., LeiM. S. (2007) Ab initio studies of structural and electronic properties of $\mathrm{Li}_{4} \mathrm{Ti}_{5} \mathrm{O}_{12}$ spinel. Electrochem. Commun., 9, 11071112. doi:10.1016/j.elecom.2007.01.013

9. Sandhya C.P., John B., Gouri C. (2014) Lithium titanate as anode material for lithium-ion cells: a review. lonics., 20, 601-620. doi:10.1007/s11581014-1113-4

10. Guo X.F., Wang C.Y., Chen M.M. et al. (2012) Carbon coating of $\mathrm{Li}_{4} \mathrm{Ti}_{5} \mathrm{O}_{12}$ using amphiphilic carbonaceous material for improvement of lithiumion battery performance. Power Sources, 214, 107-112. doi:10.1016/j.jpowsour.2012.04.097

11. Lin Y.S., Tsai M.C., Duh J.G. (2012) Self-assembled synthesis of nanoflower-like $\mathrm{Li}_{4} \mathrm{Ti}_{5} \mathrm{O}_{12}$ for ultrahigh rate lithium-ion batteries. J. Power Sources, 214, 
314-318. doi:10.1016/j.jpowsour.2012.04.072

12. Liu D.T., Ouyang C.Y., Shu J. et al. (2006) Theoretical study of cation doping effect on the electronic conductivity of $\mathrm{Li}_{4} \mathrm{Ti}_{5} \mathrm{O}_{12}$. Phys. Status Solidi B., 243, 1835-1841. doi:10.1002/ pssb.200541404

13. Lippens P.E., Womes M., Kubiak P., et al. (2004) Electronic structure of the spinel $\mathrm{Li}_{4} \mathrm{Ti}_{5} \mathrm{O}_{12}$ studied by $a b$ initio calculations and X-ray absorption spectroscopy. Solid State Sci., 6, 161-166. doi:10.1016/j.solidstatesciences.2003.12.001

14. Zhong Z.Y., Ouyang C.Y., Shi S., Lei M. S. (2008)Ab initio studies on $\mathrm{Li}_{4+\mathrm{x}} \mathrm{Ti}_{5} \mathrm{O}_{12}$ compounds as anode materials for lithium-ion batteries. ChemPhysChem, 9, 2104-2108. doi:10.1002/ cphc. 200800333

15. Samin A., Kurth M., Cao L. (2015) Ab initio study of radiation effects on the $\mathrm{Li}_{4} \mathrm{Ti}_{5} \mathrm{O}_{12}$ electrode used in lithium-ion batteries. AIP Advances, 5, 047110. doi:10.1063/1.4917308

16. Julien C. M., Massot M., Zaghib K. (2004) Structural studies of $\mathrm{Li}_{4 / 3} \mathrm{Me}_{5 / 3} \mathrm{O}_{4} \quad(\mathrm{Me}=\mathrm{Ti}$, $\mathrm{Mn}$ ) electrode materials: local structure and electrochemical aspects. J. Power Sources, 136, 72-79. doi:10.1016/j.jpowsour.2004.05.001

17. Laumann A., Boysen H., Bremholm M., et al. (2011) Lithium migration at high temperatures in $\mathrm{Li}_{4} \mathrm{Ti}_{5} \mathrm{O}_{12}$ studied by neutron diffraction. J. Chem. Mater., 23, 2753-2759. doi:10.1021/cm103332y

18. Colin J.F., Godbole V., Novák P. (2010) In situ neutron diffraction study of $\mathrm{li}$ insertion in $\mathrm{Li}_{4} \mathrm{Ti}_{5} \mathrm{O}_{12}$. J. Electrochem Comm., 12, 804-807. doi:10.1016/j. elecom.2010.03.038

19. Kitta M., Akita T., Maeda Y., Kohyama M. (2012) Study of surface reaction of spinel $\mathrm{Li}_{4} \mathrm{Ti}_{5} \mathrm{O}_{12}$ during the first lithium insertion and extraction processes using atomic force microscopy and analytical transmission electron microscopy. Langmuir, 28, 12384-12392. doi:10.1021/la301946h

20. Gao J., Jiang C., Ying J., Wan C. (2006) Preparation and characterization of high-density spherical $\mathrm{Li}_{4} \mathrm{Ti}_{5} \mathrm{O}_{12}$ anode material for lithium secondary batteries. J. Power Sources, 155, 364367. doi:10.1016/j.jpowsour.2005.04.008

21. Wang G.X., Bradhurst D.H., Dou S.X., Liu H.K. (1999) Spinel $\mathrm{Li}\left[\mathrm{Li}_{1 / 3} \mathrm{Ti}_{5 / 3}\right] \mathrm{O}_{4}$ as an anode material for lithium ion batteries. J. Power Sources, 83, 156161. doi:10.1016/S0378-7753(99)00290-6

22. Aldon L., Kubiak P., Womes M., et al. (2004) Chemical and electrochemical Li-Insertion into the $\mathrm{Li}_{4} \mathrm{Ti}_{5} \mathrm{O}_{12}$ spinel. Chem. Mater., 16, 5721-5725. doi:10.1021/cm0488837

23. Zhang Q., Liu Y., Lu H., Tang D., Ouyang C., Zhang L. (2016) $\mathrm{Ce}^{3+}$ doped $\mathrm{Li}_{4} \mathrm{Ti}_{5} \mathrm{O}_{12}$ with $\mathrm{CeO}_{2}$ surface modification by a sol-gel method for high-performance lithium ion batteries. Electrochemica Acta, 189, 147-157. doi:10.1016/j. electacta.2015.12.103
24. Zhang Q., Lu H., Zhong H., Yan X., Ouyang C., Zhang L. (2015) W6 + \& Br- codoped $\mathrm{Li}_{4} \mathrm{Ti}_{5} \mathrm{O}_{12}$ anode with super rate performance for $\mathrm{Li}$-ion batteries. J. Mater. Chem. A, 3, 13706-13716. doi:10.1039/C5TA02784E

25. Sarantuya L., Sevjidsuren G., Altantsog P., Tsogbadrakh N. (2018) Synthesis, structure and electronic properties of $\mathrm{Li}_{4} \mathrm{Ti}_{5} \mathrm{O}_{12}$ anode material for lithium ion batteries. J. Solid State Phenom, 271, 9-17. doi:10.4028/www.scientific.net/SSP.271.9

26. Rodriguez-Carvajal J., Laboratoire Léon Brillouin (2014) France.

27. Rodríguez-Carvajal J. (1993) Recent advances in magnetic structure determination by neutron powder diffraction. J. Phys. B Phys. Condens. Matter., 192, 55-69. doi:10.1016/0921-4526(93)90108-I

28. Rodríguez-Carvajal J. (2001)RecentDevelopments of the Program FULLPROF, in Commission Powder Diffraction. Newsletter, 26, 12-19.

29. Thompson P., Cox D.E., Hastings J.B. (1987) Rietveld refinement of Debye-Scherrer synchrotron X-ray data from $\mathrm{Al}_{2} \mathrm{O}_{3}$. J. Appl. Cryst., 20, 79-83. doi:10.1107/S0021889887087090

30. Perdew J.P., Burke K., Ernzerhof M. (1996) Generalized gradient approximation made simple. Phys. Rev. Lett., 77, 3865-3868. doi:10.1103/ PhysRevLett.77.3865

31. Hohenberg P., Kohn W. (1964) Inhomogeneous Electron Gas. Phys. Rev., 136, B864-871. doi:10.1103/PhysRevLett.136.B864

32. Kohn W., Sham L.J. (1965) Self-Consistent Equations Including Exchange and Correlation Effects. Phys. Rev. Lett., 140, A1133-1138. doi:10.1103/PhysRevLett.140.A1133

33. Giannozzi P., Baroni S., Bonini N., et al. (2017) Advanced capabilities for materials modelling with Quantum ESPRESSO. J. Phys.: Condens. Matter, 29, 465901. doi:10.1088/1361-648X/aa8f79

34. Vanderbilt D. (1990) Soft self-consistnent pseudopotentials in a generalized eigenvalue formalism. Phys. Rev. B, 41, 7892-7895. doi:10.1103/PhysRevB.41.7892

35. Monkhorst H.J., Pack J.D. (1976) Special points for brillouin-zone integrations. Phys. Rev. B, 13, 5188-5192. doi:10.1103/PhysRevB.13.5188

36. Blochl P.E., Jepsen O., Andersen O.K. (1994) Improved tetrahedron method for brillouin-zone integrations. Phys. Rev. B, 49, 16223-16233. https://doi:10.1103/PhysRevB.49.16223

37. Payne M.C., Teter M.P., Allan D.C., et al. (1992) Iterative minimization techniques for ab initio totalenergy calculations: molecular dynamics and conjugate gradients. Rev. Mod. Phys., 64, 10451097. doi:10.1103/RevModPhys.64.1045

38. Cococcioni M., de Gironcoli S. (2005) Linear response approach to the calculation of the effective interaction parameters in the $L D A+U$ method. Phys. Rev. B, 71, 035105. doi:10.1103/ 
PhysRevB.71.035105

39. Himmetoglu B., Wentzcovich R.M., Cococcioni M. (2011) First-principles study of electronic and structural properties of CuO. Phys. Rev. B, 84, 115108. doi:10.1103/PhysRevB.84.115108

40. Ge H., Tian H., Song H., et al. (2015) Study on the energy band structure and photoelectrochemical performances of spinel $\mathrm{Li}_{4} \mathrm{Ti}_{5} \mathrm{O}_{12}$. Mater. Res. Bull., 61, 459-462. doi:10.1016/j. materresbull.2014.10.064
41. Kim C., Norberg N.S., Alexander C.T., et al. (2013) Correction: mechanism of phase propagation during Ilthiation in carbon-free $\mathrm{Li}_{4} \mathrm{Ti}_{5} \mathrm{O}_{12}$ battery electrodes. Adv. Funct. Mater., 23, 1214. doi:10.1002/adfm.201390002 